\title{
Chapter 42 \\ Dialogues on Numbers: Script-Writing as Approximation of Practice
}

\author{
Rina Zazkis
}

\begin{abstract}
Script-writing is a novel pedagogical approach and research tool in mathematics education. The goal of this chapter is to introduce the approach and exemplify its implementation. A script-writing task presents a prompt, which usually includes an incomplete argument or erroneous claim of a student. Prospective teachers address the prompt by creating a script for a dialogue-presenting an imaginary interaction between a teacher and her students, or among different students. In this chapter I exemplify several results of implementing script-writing tasks and discuss advantages of this approach. In particular, I focus on the concepts related to elementary number theory, prime numbers and factors of a number, and demonstrate how the understanding of these concepts can be explored and refined, as script-writers create characters who discuss particular claims. I suggest that engaging prospective teachers in script-writing is one possible way to support and improve preparation of mathematics teachers.
\end{abstract}

Keywords Script-writing - Prime numbers - Role-play • Approximation of practice $\cdot$ Lesson play

\subsection{Introduction}

How can we support and improve teacher development? Mathematics educators and researchers are investigating the issue and developing a variety of approaches by which the preparation of future teachers can be enhanced. In this chapter I present one such approach - script-writing - describe how it emerged and illustrate its implementation in several cases.

Watson and Mason (2005) suggested that "the fundamental issue in working with teachers is to resonate with their experience so that they can imagine [my italics] themselves 'doing something' in their own situation" (p. 208). I attempt to

\footnotetext{
R. Zazkis $(\bowtie)$

Simon Fraser University, Burnaby, Canada

e-mail: zazkis@sfu.ca

(C) The Author(s) 2018

G. Kaiser et al. (eds.), Invited Lectures from the 13th International Congress

on Mathematical Education, ICME-13 Monographs,

https://doi.org/10.1007/978-3-319-72170-5_42
} 
access this imagination by inviting prospective teachers to write scripts that describe instructional interactions between a teacher and students.

\subsection{Script-Writing as Approximation of Practice}

Script-writing (or scripting) is a valuable pedagogical strategy and an innovative research tool which I adopted and developed within the context of mathematics teacher education. In its initial implementations, this method was referred to as "lesson play" (Zazkis et al. 2013); however, the term script-writing extends to account for interactions that are not necessarily part of a lesson. Script-writing is a tool related to "approximations of practice" (Grossman et al. 2009), which "include opportunities to rehearse and enact discrete components of complex practice in settings of reduced complexity" (p. 283), and advocated as an essential part of teacher preparation.

I consider scripting as a form of role-playing in one's imagination. As such, I briefly describe role-playing in 2.1 , focusing explicitly on role-playing on teacher education in 2.2, and then turn in 2.3 to script-writing and the use of script-writing in mathematics education. As teachers' scripts provide a lens to explore their knowledge, in $2.4 \mathrm{I}$ attend briefly to the notion of knowledge of mathematics for teaching.

\subsubsection{On Role-Playing}

Role-playing is an unscripted "dramatic technique that encourages participants to improvise behaviors that illustrate expected actions of persons involved in defined situations" (Lowenstein 2007, p. 173). In other words, role-playing is "an 'as-if' experiment in which the subject is asked to behave as if he [or she] were a particular person in a particular situation" (Aronson and Carlsmith 1968, p. 26). Role-playing is used as an effective pedagogical strategy in a variety of fields (e.g., Blatner 2009), a few of which are mentioned here.

Traditionally role-playing is used in social studies classrooms in order to provide participants with more authentic experiences of historic events and people who experienced them (e.g., Cruz and Murthy 2006). It is used to explore the complexities of social situations, such as prejudice, and ethical issues (e.g., Lawson et al. 2010; McGregor 1993; Plous 2000). Participants, after engaging in role-playing, reported being better prepared to deal constructively with everyday instances of prejudice (Plous 2000) and generated more effective responses to prejudiced comments (Lawson et al. 2010). Additionally, role-playing was used with English language learners, where teachers used role-playing in an attempt to move from a prescribed dialogue to an improvisational one. In this context, Shapiro and Leopold (2012) suggested that implementing role-playing in a classroom 
provides a "space between practice and play [which] is a fertile ground for cognitive and linguistic growth" (p. 128).

Role-playing is used in the education of various groups of professionals in organizational research, where, for example, participants assume roles of performance evaluators or interviewers of job applicants (Greenberg and Eskew 1993). It is also prevalent in the training of health professionals, where the participants play the roles of a care-giver and a patient, practicing their clinical, diagnostic and patient management skills, and as such developing empathy and tolerance in a low-risk environment (e.g., Joyner and Young 2006). However, among various uses in developing professionals, the use of role-playing in teacher education is rare.

\subsubsection{On Role-Playing in Teacher Education}

In considering role-play in teacher education, Van Ments (1983) described it as experiencing a problem under unfamiliar constraints, as a result of which one's own ideas emerge and one's understanding increases. In this sense, role-playing can also be seen as role-training. It is aimed at increasing teachers' awareness of various aspects of their actual work. Yet, despite the known advantages, role-playing in teacher education is underdeveloped. While some authors advocate for this method and report on its implementation, this is most often done in the form of self-reports and anecdotal evidence of participants' experiences.

Kenworthy (1973) described a method in which one participant takes on a teacher-role while others take on the roles of various students (e.g., a slow student, a gifted student, a disruptive student). He considered this type of role-playing to be "one of the most profitable, provocative and productive methods in the education of social studies teachers" (p. 243). He claimed that engagement in role-playing activities helped participants anticipate difficulties they encounter in their classrooms and, as such, gain security from their successful experiences should they face similar situations on the job. Assigning participants teacher and student roles was also used in a skill training workshops to deal with disturbing behaviour (Jones and Eimers 1975). Teacher training via role-playing reduced disruptive student behaviour and demonstrated gains in productivity for most students.

More recently, in Palmer (2006) study, pre-service teachers took on the roles of children as their professor modelled science teaching. It was reported that teachers' self-efficacy increased and they were more open to the idea of implementing role-playing in their teaching. In Howes and Cruz (2009) research, students in an elementary science methods class were invited to assume roles of scientists and take part in an "Oprah Show" interview. In addition to learning about contributions of different scientists, this activity sharpened the prospective teachers' understanding of what science is and what image of science they wished to convey to their students. 
In mathematics teacher education, role-playing tasks were used to provide an opportunity to imagine personal responses to a variety of situations (e.g., Maheux and Lajoie 2011; Lajoie and Maheux 2013). To extend participation, Lajoie and Maheux engaged groups of prospective teachers in planning the roles of different players in a given instructional situation, and then called upon representatives from the groups to enact the role-play.

\subsubsection{On Script-Writing}

Despite the recognized advantages, time and participation logistics cause significant limitations in role-playing. If we engage students in role-playing during class, only a few will be active players, while the majority will serve as the audience. To afford all students the opportunity to participate in a player's role, I introduced imagined role-playing, i.e., writing a script for a dialogue between characters: teacher and student(s). In this approach, participants are presented with a prompt that describes a problematic situation, a disagreement, a student error, or inappropriate reasoning. The script-writing task is to devise a dialogue between the characters that leads to a resolution.

Script-writing is novel in mathematics education research. Its roots, however, trace to the Socratic dialogue, a genre of prose in which a wise man leads a discussion, often pointing to flaws in the thinking of his interlocutor. The method echoes the style of Lakatos (1976) evocative Proofs and Refutations in which a fictional interaction between a teacher and students clarifies mathematical concepts and claims.

Initially, script-writing was introduced in mathematics teacher education as a "lesson play" (Zazkis et al. 2009, 2013). Juxtaposed to a classical lesson plan describing merely content and activities, the lesson play reveals how a teaching-learning interaction unfolds. Using the theatrical meaning of the word 'play', lesson play refers to a task in which teachers are asked to write a script for a lesson, or part of a lesson, presented as a dialogue between a teacher and students. The task was developed as a result of dissatisfaction with the traditional approach of creating "lesson plans", often used in teacher education. The lesson play was advocated as a tool for preparing to teach, as a diagnostic tool for teacher educators, and as a tool for researchers studying issues of didactics and pedagogy (Zazkis et al. 2013).

The evolution of lesson play tasks from a general request to create a 'play' to carefully designed prompts on which plays are based is described in Zazkis et al. (2013). In short, in the initial implementation of lesson plays, it was noted that prospective teachers attempted to avoid any 'problematic' situations, such as dealing with explicit student mistakes or misconceptions. We then refined the general instructions, asking teachers to address in their plays a student mistake or some "problematic issue". The resulting plays exemplified some variation of the following template: the teacher asks a question, student-A provides a wrong 
answer, a teacher asks whether someone has a different answer, student-B provides a correct answer, the teacher reiterates the correct answer, praises student-B and moves to a new question.

The explicit instruction that the plays should address some problematic situation made us realize that prospective teachers had a very limited repertoire of potential problems that students experience. Therefore, in later implementations, prospective teachers were presented with the beginning of a dialogue, referred to as a 'prompt', and asked to continue the conversation. The prompts usually presented a student's erroneous answer; the teachers were asked to identify what could have led to this error and how a conversation could guide a student towards a resolution. Furthermore, the teachers were explicitly asked to describe the setting, as they imagined it, in which the presented prompt took place.

Script-writing is both an instructional tool and a research tool for data collection. For example, in recent studies it was implemented to investigate prospective teachers' understanding of particular proofs (Koichu and Zazkis 2013; Zazkis 2014; Zazkis and Zazkis 2016), central concepts in geometry and number theory (Kontorovich and Zazkis 2016; Zazkis and Zazkis 2014), and the use of particular symbols (Zazkis and Kontorovich 2016). The participants had to identify problematic issues in the presented proofs or topics, and then clarify these by designing a scripted dialogue. The scripts revealed participants' personal understandings of the mathematical concepts involved, as well as what they foresaw as potential difficulties for their imagined students, and how they may address these difficulties by building on their knowledge of mathematics for teaching.

\subsubsection{Scripts as a Window on Knowledge of Mathematics for Teaching}

Knowledge of mathematics in and for teaching has received significant attention in mathematics education research (e.g., Rowland and Ruthven 2011). What appears to unify different and seemingly opposing perspectives is a view that teachers' mathematical knowledge is complex and has distinctive features that deserve research attention.

In this chapter, I illustrate how teachers' scripts provide a window to explore, and subsequently an opportunity to enhance, their knowledge of mathematics, and of teaching mathematics. Sections 42.3 and 42.4 exemplify research-informed design of prompts and provide excerpts from scripts composed by prospective elementary school teachers in response to these prompts. The excerpts are chosen to illustrate particular repeating approaches in imagining instructional interaction. At the time of data collection, the participants completed a unit on number theory (focusing on concepts of divisibility, factors and multiples, prime and composite numbers) in a "Principles of Mathematics" course designed explicitly for elementary school teachers. 


\subsection{Identifying Prime Numbers}

What exactly is a prime number and how can it be identified? To investigate how prospective elementary school teachers address this question, they were invited to develop scripts (lesson plays) starting with the following prompts:
(A) Teacher Why do you say 143 is prime?
Johnny Because 2, 3, 4, 5, 6, 7, 8 and 9 don't go into it.
(B) Teacher Why do you say 37 is prime?
Johnny Because 2, 3, 4, 5, 6, 7, 8 and 9 don't go into it.

These prompts were developed based on the experience of teaching prospective elementary school teachers and on research conducted on their understanding of number theory related concepts. In particular, Zazkis and Liljedahl (2004) demonstrated that frequently the primality of a number is determined by checking the divisibility of a given number by small numbers only, at times focusing only on numbers for which divisibility rules were known. This served as a basis for prompt A.

In prompt B there is no apparent mistake; unlike 143, 37 is indeed a prime number. This prompt aimed at focusing prospective teachers' attention on the strategy the student employed to determine primality, rather than on working towards a correct answer.

The teachers were asked to develop an instructional situation in which they address Johnny's response. They could include other students in the conversation, as they found appropriate.

\subsubsection{Following Prompt A}

The main approaches ${ }^{1}$ used in scripting a conversation were: attending to the size of possible factors and inviting students to consider factors larger than 9 (see Sect. 42.3.1.1), and using the divisibility rules (see Sect. 42.3.1.2).

\subsubsection{On the Size of Factors}

The following excerpt invites students' reflection on the existence of factors larger than 9 . The conversation presented below continues after it has been confirmed that the numbers 2-9 were not factors of 143 .

\footnotetext{
${ }^{1}$ My goal in this chapter is to exemplify several ideas attended to in the scripts, rather than to enumerate the occurrences.
} 
T: Can a number that is bigger than 9 be a factor for a number?

S: I do not know, maybe.

[...]

T: Well now let's take the number 100 for a moment because it is nice and simple.

Can 2 go into 100?

S: Yes.

T: How do you know?

S: Because $2 \times 50=100$.

$\mathrm{T}$ : And what is the divisibility rule that we just learned that can also help us?

S: 100 is an even number that ends in zero, so it is divisible by 2 .

T: Good. So we know that 2 is a factor of 100 , but is 50 not also a factor of 100 ?

$\mathrm{S}$ : Yes, 50 is a factor.

$\mathrm{T}$ : But 50 is a lot bigger than the number one and it still counts?

S: I guess so.

$\mathrm{T}$ : Okay, so knowing that a number can have factors that are bigger than nine, I want everyone to get out their calculators and see if they can find other factors for 143. It's fine to use trial and error for this question.

The play proceeds with the expected discovery of the factors of 143 and the expected conclusion. However, while this excerpt clearly shows a number (100) with a factor greater than 9 (50), it does not necessarily address the source of Johnny's difficulty, because 100 also has small number factors, like 2 and 5 . However, the claim in the prompt that a number that is not divisible by $2-9$ is prime is not based on the belief that a number cannot have a 'large' factor; rather, it is based on the belief that a small factor is always present. Such a belief was explored in Zazkis and Campbell (1996b) and in Zazkis and Liljedahl (2004). In particular, participants in these studies expected divisibility of composite numbers by "small primes," and this expectation co-existed with their awareness of infinitely many primes. This expectation is explained by a student in Zazkis and Campbell (1996b) study, who reasons that "when you factor a number into its primes [...] just the whole idea of factoring things down into their smallest parts [...] gives me an idea that those parts are themselves going to be small" (p. 216). As such, finding factors of 143 (with the help of a calculator), as the teacher directs students to do at the end of this excerpt, changes the students' ideas with respect to the primality of 143 , but does not address the source of the presented confusion.

\subsubsection{Focus on Divisibility Rules}

While most scripts made use of divisibility rules (to determine or to confirm that numbers from 2 to 9 are not factors of 143), the following excerpt features the introduction of the divisibility rule for 11 . But before getting to this divisibility rule, the class is invited to revisit what a prime is and what a factor is; then the play continues. 
T: $\quad$ Okay class, did you wonder if 143 is divisible by numbers bigger than 9 ?

Johnny: No, because if 2-9 won't divide into 143 then any number made up of those numbers won't divide into it.

T: $\quad$ I see, well, what if we look at numbers higher than $9 \ldots$ what about 10 ?

Johnny: No, because the number would have to end in a zero to be divided by 10 , like 100.

T: $\quad$ I see. Well do we know the rules for numbers higher than 10 ?

Johnny: No, I do not remember learning them.

$[\ldots]$

Sue: Well, I tried 11.

$\mathrm{T} \quad$ How did you try 11 ?

(Sue shows a calculator)

T: $\quad$ Does anyone know the divisibility rule for 11 ?

Bobby: Yeah. For 11 you take the number (T writes 143 on the board) subtract the last digit from the first two, which equals 11 (writes $14-3=11$ ). The answer is 11 so yes, 143 is divisible by 11 .

(Johnny writes down the rule and tries to solve the problem himself)

Johnny: Well I see now that 11 goes into $143 \ldots$ so what is the other number? T: $\quad$ Well, why don't we do the long division as a class. $11 / 143 \ldots$ How many times? Please work it out on your paper and put your hand up when you have the answer.

As is often the case in the plays, there is at least one student who recalls the desired rule. In fact, only a particular case of divisibility by 11 is demonstrated, but this does not appear to bother the teacher.

Sue's discovery of 11 being a factor 143, with the help of a calculator, is pushed aside by the teacher, who prefers to focus on divisibility rules. Further, the suggested strategy to find "the other number," that is, the other factor of 143 , is to use long division. The developed script leaves the impression that performing division with a calculator is insufficient to reach a conclusion related to divisibility, that preference is given to rules or algorithms.

When it is confirmed that the 'rule' applies to 143, Johnny asks about the other factor of 143. The teacher invites the class to work on long division "as a class" (and it is interesting to consider why the teacher wants everyone to do it) in order to answer Johnny's question. But another way of addressing Johnny would be to ask whether the other factor is indeed needed. The teacher could use this opportunity to help students realize that only one factor is required to conclude that 143 is a composite number.

It is rather surprising that the script-writer assumed that elementary school students would be familiar with divisibility rules for 11 or 13 . Those rules, which can be developed for any prime number, reveal some fascinating relationships among numbers (Eisenberg 2000). However, divisibility tests in the "calculator era" have little utility. The divisibility rules for 7 and beyond 10 are rarely discussed in 
current curricula for elementary school students or for prospective teachers of mathematics. Instead of using the rule as a method for determining divisibility, we see its role today more as an opportunity to engage in mathematical reasoning: either to develop, test and refine conjectured rules or to try to understand how and why the rules work.

Overall, teachers' dependence on divisibility rules presents a concern. It appears that, for them, the notion of divisibility is connected to a specific rule rather than to the multiplicative relationship of numbers. The rule is valued much more than other means of determining divisibility, such as long division or a calculator.

\subsubsection{Following Prompt B}

Even though all the scripts either acknowledged or checked that indeed 143 is not divisible by numbers smaller than 10, no script-writer seemed to question this strategy. That is, having acknowledged that the number is not divisible by 2 and 3 , why was there a need to check for divisibility for 4,6 or 9 ? It was in order to focus on the strategy, rather than the correctness of the decision, that script-writers were presented with prompt B.

In this case, the number under investigation is indeed prime, but the suggested student's answer includes unnecessary information and may again hint at an inappropriate strategy for checking for primes. However, the student strategy, refined in Sect. 42.3.2.1, was not the focus of most plays, rather, the focus was on the definition of primes (see Sect. 42.3.2.2) and on divisibility rules (Sect. 42.3.2.3).

\subsubsection{Focus on Prime Factors (Only)}

In the following excerpt, the strategy for determining primality of a number was explicitly acknowledged by a student-character. The conversation between two students in the excerpt below takes place after the teacher asked the class whether they agreed with the conclusion presented in the prompts and attributed to Student 1 .

Student 2: We only need to divide 37 by other primes. That is, for 37 you could try $2,3,5$ and 7 . You could stop at 7 , as $7 \times 7=49$ which is bigger than 37. All the other numbers are composite numbers using these primes. So if the primes don't divide the number the composite cannot either.

Student 1: So I do not need to try and divide all the numbers into 37 to see if it is prime?

Student 2: All you have to do to find out if a number is prime is divide it by other prime numbers that if multiplied by themselves would be less or equal to the number you are looking at.

(the lesson continues in a different direction)

A correct strategy, which is an alternative to "try and divide all the numbers into 37 ," is attributed to Student 2 . However, while the strategy is correctly summarized, 
the reason for it is not mentioned by the student and is not sought by the teacher. Further, the implementation of the strategy exemplified in this excerpt is different from the description of the strategy. That is, according to the description, one can stop at 5, while Student 2 explicitly claims "You could stop at 7 , as $7 \times 7=49$ which is bigger than 37." Of course, there is no harm in checking divisibility by an additional prime number, even if it is inconsistent with the cited approach. It often happens that teachers can correctly describe the strategy for determining primality of a number, likely reciting what was learned, but they seem to lack trust in implementing it (Zazkis and Liljedahl 2004). That is, having checked divisibility by all the primes whose square is less than the number in question, they continue to check divisibility by other numbers, both prime and composite, "just in case" or "to be on the safe side." These actions are often connected to an inability to explain why only particular primes are to be considered. The lack of confidence in implementing the described strategy points to the potential lack of understanding of the strategy.

\subsubsection{Focus on the Definition of Primes}

The following excerpt begins with a discussion about the definition of primality, which exemplifies a common move (return-to-definition) in the lesson plays. There is no challenge to the approach used by Johnny.

T: What you say is true, but that's not how a prime number is defined. Do you remember the definition of a prime number?

S: Yea, sort of. A number that you can only divide by itself and one. Like 2, right?

T: Exactly. It can divide itself evenly. So what do we know about 37, if it is prime?

S: That it can be evenly divided by 1 and 37 .

T: Great. So let's talk about the numbers you picked to try to divide 37. From 2 to 9. Can you please explain why you concluded that these numbers don't work?

S: I guess and checked with numbers 2-9 and I proved that it was prime. No matter what the divisor, unless it is 1 and 37, will not work.

$\mathrm{T}$ : Excellent. I think what we talked about is really useful; after all, the idea of prime numbers is quite difficult. I think I will get the class to stop their work and get them in their groups talking about prime numbers.

Let us focus on the teacher's response to a student's reasoning about why 37 is a prime number. Initially, the teacher appears satisfied with the student's conclusion, but not the reason for it because "that's not how a prime number is defined." It appears that there is an implicit expectation that a definition for a prime will be cited, rather than the results of checking for primality. A student recalls a definition of a prime as "A number that you can only divide by itself and one. Like 2, right?". Here, while the language attributed to a student can be improved, the teacher's rephrasing - "it can divide itself evenly" - does not communicate the idea of a 
number being prime. An extended discussion on the language related to number theory concepts is found in Zazkis et al. (2013). I bring this issue here to demonstrate that the scripts provide an opportunity to address the language of mathematics used by prospective teachers, both as a venue for analysis, and as a discussion in class.

Further, when the student offers the example of 2, the teacher does not take the opportunity to explore other examples, especially ones that are not even (and that might push on the student's idea of what dividing evenly might mean). Yet again I highlight this point to demonstrate that focusing on the examples found in scripts provides an additional layer of analysis, as well as the basis for a discussion with teachers on the choice of instructional examples.

\subsubsection{Searching for a Number with Prime Factors Larger Than 9}

In the next excerpt, the script-writer attempts to work on the problematic strategy proposed by Johnny. The following dialogue takes place after the definition of prime numbers was revisited.

Ms. L: Turn to your group of 3 and I'll give you your challenge. Your challenge is to find a number that is not a prime number and is also not divisible by $2,3,4,5,6,7,8$ or 9 . I will tell you that you don't need to look higher than 150 .

Student 1: We have to test every number between 100 and 150 to see if it's divisible by 11 and 13 .

Student 2: We don't need to test any even number since we know it's already divisible by 2 .

Student 3: Oh yeah! And we don't have to test the numbers that end in 5 or 0 because they can be divided by 5 !

Student 2: Here, let's use the whiteboard and write al the numbers it could be. (Students write 101, 103, 107, 109, 111, etc. to 150.)

Student 1: Oh, and remember Ms. L said that a number that has all its digits add up to something that can be divided by 3 means the whole number can be divided by 3 . Yeah, that's one of the rules we wrote.

Student 2: Guys! Why don't we just use that list of divisibility tricks we made up in the first part of the class to cross off the other numbers? Then we won't have to do so much division. Our rules are still up on the board. Is that right, Ms. L.?

(Students cross off numbers and are left with this list: 101, 103, 107, $109,113,121,127,131,137,139,143,149$.)

Student 2: Now all we have to do is to test if those 12 numbers are divisible by 11 and 13 
(Sharing the long division work, students find 121 and 143.)

Student 3: Ms. L., Look, we figured it out. It's 121 and 143! All the rest of the numbers up there are prime.

Ms. L: $\quad$ And 121 and 143 are what then?

Student 3: 121 and 143 are numbers that are not prime but they also don't divide by $2,3,4,5,6,7,8$ or 9 .

Ms. L: $\quad$ So are the divisibility rules from 2 to 9 always going to work to discover non-prime numbers?

Student 1: Nope!

Here, the attention has been diverted from the specific case of 37 , and the students are working explicitly to produce an example where testing divisibility by the numbers from 2 to 9 is insufficient to conclude primality of a number. The students first sieve out multiples of numbers smaller than 10 from the list of numbers from 100 to 150 , relying on divisibility rules that "are still up on the board", then check divisibility of the remaining numbers by 11 and 13 , which results in identifying 121 and 143.

Students discover that checking divisibility by numbers from 2 to 9 is insufficient, or, in the words of the teacher not "always going to work to discover non-prime numbers." It is interesting to note that while the intention in this prompt was to focus on unnecessary steps in checking for primality of 37 , this playwright focused on the strategy as being insufficient in some cases.

Despite the strength of this approach, there are further opportunities for the teacher to focus students' attention more squarely on the notion of primality than on numerical operations (division, especially). For example, while the students used their knowledge of divisibility rules and long division to find 121 and 143, the teacher might have intervened to show how these numbers can be constructed multiplicatively as $11 \times 11$ and $11 \times 13$. While it is possible that this particular script-writer will direct students' attention to the matter in the next lesson, research has shown that the connection between multiplication and division is frequently unaddressed in dealing with number theory related tasks. For example, prospective elementary teachers, when asked to find a 'large' 5-digit number divisible by 17 prefer to check for divisibility with calculator, rather than construct such a number by multiplying 17 by a 3 or 4-digit number (Hazzan and Zazkis 1999). Further, when asked to find a number with exactly 4 factors, participants' preferred strategy was to guess and check, rather than construct such a number as product of 2 primes (Zazkis and Campbell 1996a). As such, the strategy of sieving multiples of 2-9 on the list of numbers from 100 to 150 might have been the main approach that was available to the script-writer. As mentioned previously, presenting this approach for the scrutiny of prospective teachers can enrich their understanding of mathematics, which, in turn, shapes their pedagogical approaches. 


\subsection{Numbers and Their Factors}

Is there a relationship between the size of a number and the number of its factors? To discuss this relationship, prospective teachers were presented with the following scenario:

Bonnie and Clyde are discussing numbers and their factors. Bonnie claims that the larger a number gets, the more factors it will have. Clyde disagrees.

This prompt was developed as a result of having faced the repeated belief of students that the larger a number gets, the more factors it is expected to have (Zazkis 1999). This belief is consistent with the family of "intuitive rules" of the kind "more of A, more of B" discussed by Stavy and Tirosh (1996, 2000). For example, the erroneous idea that rectangles with a larger perimeter have larger areas is a frequent result of the reliance on this rule.

Prospective teachers were asked to develop a script for a conversation between these two characters that included their exchange of arguments. In particular, they were asked to consider examples and experiences that could have led Bonnie to this conclusion, the arguments that both sides use to convince each other, and what each one of them finds convincing. They were further asked to annotate the script analyzing the arguments of the characters and their examples.

The common tendency related to true or false decisions is exemplified in Sect. 42.4.1, a tendency to consider disconfirming evidence as particular counterexamples is discussed in Sects. 42.4.2 and 42.4.3. Furthermore, the particular role of the choice of examples to build a convincing, or a more convincing, argument is attended to in Sect. 42.4.4.

\subsubsection{Who Is Right?}

While no participant agreed with Bonnie (that larger numbers have more factors), there were various degrees of disagreement. A few scripts demonstrated a view in accord with mathematical convention by clearly rejecting Bonnie's claim. This is exemplified in the following:

Clyde: The answer to "True or False": As a number gets bigger the more factors it will have" is False. It may sometimes have more factors, but to say that it always does would be incorrect.

However, the verdict of 'false' to a statement that is 'sometimes true', or true in a large number of cases, is inconsistent with everyday reasoning. As such, even when a mathematically correct conclusion was drawn, some participants attempted to amend the theory by referring to a limited scope of applicability. Theory amendment is in accord with a mathematical/scientific norm in response to disconfirming evidence (Chinn and Brewer 1993), however, the amendment itself was usually 
incorrect. For example, consider the following views included in the commentary: "Large numbers do not always have more factors. [...] Her statement could be true for even numbers that are increasing but it is not true for all numbers as a collective".

This statement exemplifies that a common tendency was to consider that Bonnie was "not totally wrong", "not completely right", or "only partly correct". This is consistent with intuitive application of fuzzy logic (e.g., Zazkis 1995) to a mathematical situation. Further, prime numbers were the most notable exceptions from the perceived 'rule', which is in accord with Chinn and Brewer (1993) category of "excluding data from the currently held theory", as is exemplified below.

\subsubsection{Prime Numbers as Exceptions}

Prime numbers immediately falsify Bonnie's initial claim. All script-writers attended to prime numbers, but this attention had different forms. Initial examples of small primes - such as 5 has fewer factors than 4 , or that 7 has fewer factors than 6 - were initially treated by Bonnie in many of the scripts as an anomaly. Consider the following reaction to disconfirming evidence:

Clyde: Exactly! Now haven't we just shown that larger numbers don't always have more factors?

Bonnie: Damn you and your tricks! No, I refuse to give in, maybe you have just selected the only two numbers that this general rule does not apply to. Maybe you chose an anomaly, the only exception to the rule; it's going to take more than just one counter example to persuade me!

Providing evidence that supports the claim was the usual reaction to the initial disconfirming evidence. However, as exemplified on the following commentary, "Bonnie is selecting only composite numbers, and that is her mistake, she seems to be forgetting that there are more than just composite numbers." This comment implicitly suggests that the script-writer may believe the statement to be correct for all composite numbers, that is, leaving out the primes. Other script-writers attributed this perception to their characters explicitly, as exemplified in the following excerpt:

Bonnie: The larger the number, the more factors it has.

Clyde: True, unless it's a PRIME NUMBER.

Bonnie: Why didn't you tell me this rule before, it could have helped save so much time!

Clyde: I wasn't sure myself either, I just didn't want you to think you were right so I denied it.

Students' tendency to reject evidence that is not in accord with their held beliefs was noted in several studies (e.g., Chinn and Brewer 1993; Edwards 1997). Given that script-writers were prospective teachers, this tendency of their script characters 
exemplifies their awareness of such behavior among students. However, in the assignment the participants were asked to acknowledge the erroneous claims of their characters in the accompanying commentary. When the characters' erroneous decisions were not noted, they are likely to be in accord with the script-writers' personal views. Excluding prime numbers from the generally accepted 'rule' was the most frequent conclusion attributed to Bonnie's character.

\subsubsection{Powers of Primes as Exceptions}

While prime numbers were the most frequently acknowledged exceptions, they were not seen as the only exceptions to the 'rule'. The other conclusion was to exclude powers of primes from the general assertion. The following dialogue was presented after several examples of prime numbers have been considered.

Bonnie: Prime numbers are the exception to the rule. They do not behave like other numbers. [...] The numbers that I am talking about when I say that the factors increase as the value of the numbers increase, are any number other than a prime.

Clyde: Okay, so what about the squares of prime numbers. For example, the square of 7 is 49 , so its only factors are 1,7 and 49 . That means that a smaller number, like 12, actually has more factors than the larger number which is 49. I am confused.

Bonnie: Again, Clyde, we are looking at prime numbers in this situation. Any square of a prime will only have three factors just like you said. The same thing happens when you find the number of factors in the cube of a prime. But remember what I said before: prime numbers are the exception to the rule. [...] when leaving out numbers that can be factored into the base of a prime number, like you said, the rule does hold true.

Here Bonnie acknowledges prime numbers as exceptions, but later she is invited to look at squares of primes. As a result, the 'exceptions' to the rule are extended to include powers of primes. Though the expression "numbers that can be factored into the base of a prime number" used by both characters is colloquial, it is clear from the examples that this phrase refers to numbers whose prime factorization is a power of a single prime. This is yet another example of theory amendment, while the amendment itself is incorrect. As the script-writer does not comment on Bonnie's conclusion - that "the rule does hold true" once some numbers are excluded-it is likely that the teacher shared this belief. Other possible clusters of possible 'exceptions', such as the product of two large primes, were not discussed in any of the scripts. 


\subsubsection{On Counterexamples and Large Numbers}

In all the scripts one counterexample was insufficient in convincing Bonnie to abandon her claim (recall Bonnie's claim in Sect. 42.4.1, "it's going to take more than just one counter example to persuade me!"). This shows the awareness of script-writers of the possible robust beliefs of their potential students, beliefs that they themselves may also possess. The following statement in a script-write's commentary summarizes this phenomenon:

Bonnie insisted she was right until Clyde did more examples to prove her wrong. In order to thoroughly prove that this theory is a reliable one (without just taking someone's word for it), one must test the theory multiple times with various numbers. After picking a few strategic numbers, only a few examples are required before the trend can be seen that the size of the number does not influence the number of factors.

The tendency to treat counterexamples as exceptions, as in the case of 'large primes', was mentioned previously. However, counterexamples that included 'large' composite numbers that were close to each other had more convincing power than others. For example, comparing the number of factors of 512 (having 10 factors) and 513 (having 8 factors), or, in a different script, comparing the factors of 3800 and 3600 helped Bonnie reconsider her position. The script-writers demonstrated not only that several examples are essential, but also that examples with large numbers are - using a notion introduced by Mason (2006) - more 'exemplary', that is, are more likely to serve the intended purpose.

Attention to large numbers is an additional extension to the list of responses to "anomalous data" identified by Chinn and Brewer (1993): rechecking the evidence with additional and more convincing examples. Perhaps this extension is applicable to mathematics settings more than science settings.

\subsection{Discussion}

There are numerous advantages of the script-writing task for teachers, for teacher educators and for researchers. For teachers, advantages include the opportunity to examine their personal responses to students' erroneous perspectives, understand their origin and consider how students can be helped in overcoming their errors. Furthermore, scripting presents teachers with an opportunity to examine and extend their personal understanding of mathematics, without the need to "think on their feet", and to develop personal repertoires of general strategies to be used in future improvisations. As an "approximation of practice" (Grossman et al. 2009), expressing ideas in a form of a scripted dialogue affords a more thoughtful and pre-planned (rather than "real-time") response.

For mathematics teacher educators and researchers, there is an assumption that, when writing scripts, the writers present their personal views in the teacher's role. My experience suggests that even when a script involves a conversation among 
students, such as in the Bonnie and Clyde scenario, one of the characters acts in a "teacherly" mode. As such, advantages of scripting tasks for teacher educators include the opportunity to highlight a variety of appropriate pedagogical responses and direct teachers' further attention to learners. It is an opportunity to move beyond traditional "lesson planning", as a preparation for instruction. Script-writing introduces further variety to the tasks for prospective teachers in the design of "methods" courses.

For researchers, implementing scripting tasks provides a lens to examine teachers' ideas and discourse via their imagined actions and chosen words. It provides an opportunity to analyze both mathematical understanding and the chosen instructional approaches.

The goal of this chapter is to present an argument for, and exemplify the use of, script-writing tasks in mathematics teacher education and research. In the examples presented in Sect. 42.3, it is clearly demonstrated that prospective teachers are more comfortable to attend to student errors (reacting to the claim that 143 is prime) than to correct claims (that 37 is prime) followed by inefficient and incomplete justifications. This creates the need for further development of prompts in which correct answers are presented as a result of incorrect or insufficient reasoning and to extend a conversation with teachers that strengthens their attention to students' reasoning rather than to the correctness of the answer.

Furthermore, the examples presented in Sect. 42.4 highlight the teachers' tendency to implement fuzzy logic (e.g., Zazkis 1995), where the "middle ground" is sought between true and false. This accentuates the need for an explicit conversation on how the truth value of mathematical statements is determined, the issue that often remains implicit when mathematical encounters for prospective elementary teachers are considered.

Seeking ways to support and improve mathematics teacher education is a continuous challenge. I argue that engaging prospective teachers in script-writing is one possible way to address this challenge. Overall, the script-writing tasks, and the scripts written by prospective teachers, contribute to mathematics education on two arenas: they inform research on teachers' knowledge, and support instructional design in teacher education courses.

\section{References}

Aronson, E., \& Carlsmith, J. M. (1968). Experimentation in social psychology. In G. Lindzey \& E. Aronson (Eds.). The handbook of social psychology (Vol. 2, pp. 1-79). Reading, MA: Addison-Wesley.

Blatner, A. (2009). Role playing in education. Available: http://www.blatner.com/adam/pdntbk/ rlplayedu.htm.

Chinn, C. A., \& Brewer, W. F. (1993). The role of anomalous data in knowledge acquisition: A theoretical framework and implications for science instruction. Review of Educational Research, 63(1), 1-49. 
Cruz, B., \& Murthy, S. (2006). Breathing life into history: Using roleplaying to engage students. Social Studies and the Young Learner, 18(3), 4-8.

Edwards, L. D. (1997). Exploring the territory before proof: Students' generalizations in a computer microworld for transformation geometry. International Journal of Computers for Mathematical Learning, 2, 187-215.

Eisenberg, T. (2000). On divisibility by 7 and other low-valued primes. International Journal for Mathematics Education in Science and Technology, 31, 622-626.

Greenberg, J., \& Eskew, D. E. (1993). The role of role-playing in organizational research. Journal of Management, 19(2), 221-241.

Grossman, P., Hammerness, K., \& McDonald, M. (2009). Redefining teaching, re-imagining teacher education. Teachers and Teaching: Theory and Practice, 15(2), 273-289.

Hazzan, O., \& Zazkis, R. (1999). A perspective on "give an example" tasks as opportunities to construct links among mathematical concepts. Focus on Learning Problems in Mathematics, 21(4), 1-14.

Howes, E. V., \& Cruz, B. C. (2009). Role-playing in science education: An effective strategy for developing multiple perspectives. Journal of Elementary Science Education, 21(3), 33-46.

Jones, F. H., \& Eimers, R. C. (1975). Role-playing to train elementary teachers to use a classroom management "skill package." Journal of Applied Behavior Analysis, 8, 421-433.

Joyner, B., \& Young, L. (2006) Teaching medical students using role play: Twelve tips for successful role plays. Medical Teacher, 28(3), 225-229.

Kenworthy, L. S. (1973). Role-playing in teacher education. Social Studies, 64(6), 243-247.

Koichu, B., \& Zazkis, R. (2013). Decoding a proof of Fermat's little theorem via script writing. Journal of Mathematical Behavior, 32, 364-376.

Kontorovich, I., \& Zazkis, R. (2016). Turn versus shape: Teachers cope with incompatible perspectives on angle. Educational Studies in Mathematics, 93(2), 223-243.

Lajoie, C., \& Maheux, J.-F. (2013). Richness and complexity of teaching division: Prospective elementary teachers' roleplaying on a division with remainder. In B. Ubuz (Ed.), Proceedings of the Eighth Congress of European Research in Mathematics Education (CERME 8), Manavgat-Side, Antalya, Turkey.

Lakatos, I. (1976). Proofs and refutations. Cambridge: Cambridge University Press.

Lawson, T. J., McDonough, T. A., \& Bodle, J. H. (2010). Confronting prejudiced comments: Effectiveness of a role-playing exercise. Teaching of Psychology, 37, 256-261.

Lowenstein, A. J. (2007). Role play. In M. J. Bradshaw \& A. J. Lowenstein (Eds.), Innovative teaching strategies in nursing (4th ed., pp. 173-182). Boston, MA: Jones and Bartlett.

Maheux, J.-F., \& Lajoie, C. (2011). On improvisation in teaching and teacher education. Complicity: An International Journal of Complexity and Education, 8(2), pp. 86-92.

Mason, J. (2006). What makes an example exemplary: Pedagogical and didactical issues in appreciating multiplicative structures. In R. Zazkis \& S. R. Campbell (Eds.), Number theory in mathematics education: Perspectives and prospects (pp. 41-68). Hillsdale, NJ: Lawrence Erlbaum Press.

McGregor, J. (1993). Effectiveness of role playing and antiracist teaching in reducing student prejudice. Journal of Educational Research, 86(4), 215-226.

Palmer, D. H. (2006). Sources of self-efficacy in a science methods course for primary teacher education students. Research in Science Education, 36, 337-353.

Plous, S. (2000). Responding to overt displays of prejudice: A role playing exercise. Teaching of Psychology, 27(3), 198-201.

Rowland, T., \& Ruthven, K. (Eds.) (2011). Mathematical knowledge in teaching. Springer.

Shapiro, S., \& Leopold, L. (2012). A critical role for role-playing pedagogy. TESL Canada Journal, 29(2), 120-130.

Stavy, R., \& Tirosh, D. (1996). Intuitive rules in science and mathematics: The case of "more of A -more of B". International Journal of Science Education, 18(6), 653-667.

Stavy, R., \& Tirosh, D. (2000). How students (mis-)understand science and mathematics: Intuitive rules. New York: Teachers College Press. 
Van Ments, M. (1983). The effective uses of role-play: A handbook for teachers and trainers. London: Kogan Page.

Watson, A., \& Mason, J. (2005). Mathematics as a constructive activity: Learners generating examples. Mahwah, NJ: Lawrence Erlbaum.

Zazkis, D. (2014). Proof-scripts as a lens for exploring students' understanding of odd/even functions. Journal of Mathematical Behavior, 35, 31-43.

Zazkis, D., \& Zazkis, R. (2016). Prospective teachers' conceptions of proof comprehension: Revisiting a proof of the Pythagorean theorem. International Journal of Mathematics and Science Education, 14, 777-803.

Zazkis, R. (1995). Fuzzy thinking on non-fuzzy situations: Understanding students' perspective. For the Learning of Mathematics, 15(3), 39-42.

Zazkis, R. (1999). Intuitive rules in number theory: Example of "the more of A, the more of B" rule implementation. Educational Studies in Mathematics, 40(2), 197-209.

Zazkis, R., \& Campbell. S. R. (1996a). Divisibility and multiplicative structure of natural numbers: Preservice teachers' understanding. Journal for Research in Mathematics Education, 27(5), 540-563.

Zazkis, R., \& Campbell. S. R. (1996b). Prime decomposition: Understanding uniqueness. Journal of Mathematical Behavior, 15(2), 207-218.

Zazkis, R., \& Liljedahl, P. (2004). Understanding primes: The role of representation. Journal for Research in Mathematics Education, 35(3), 164-186.

Zazkis, R., \& Kontorovich, I. (2016). A curious case of superscript (-1): Prospective secondary mathematics teachers explain. Journal of Mathematical Behavior, 43, 98-110.

Zazkis, R., Liljedahl, P., \& Sinclair, N. (2009). Lesson plays: Planning teaching versus teaching planning. For the Learning of Mathematics, 29(1), 40-47.

Zazkis, R., Sinclair, N., \& Liljedahl. P. (2013). Lesson play in mathematics education: A tool for research and professional development. Dordrecht, The Netherlands: Springer.

Zazkis, R., \& Zazkis, D. (2014). Script writing in the mathematics classroom: Imaginary conversations on the structure of numbers. Research in Mathematics Education, 16(1), 54-70.

Open Access This chapter is licensed under the terms of the Creative Commons Attribution 4.0 International License (http://creativecommons.org/licenses/by/4.0/), which permits use, sharing, adaptation, distribution and reproduction in any medium or format, as long as you give appropriate credit to the original author(s) and the source, provide a link to the Creative Commons license and indicate if changes were made.

The images or other third party material in this chapter are included in the chapter's Creative Commons license, unless indicated otherwise in a credit line to the material. If material is not included in the chapter's Creative Commons license and your intended use is not permitted by statutory regulation or exceeds the permitted use, you will need to obtain permission directly from the copyright holder.

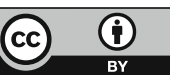

